\title{
Modeling Policyholder Behavior through Insurance Resonant Marts for Pricing Options and Guarantees
}

\author{
S. Jayaprakash ${ }^{1}$, Michael $\mathrm{Ha}^{2}$ \\ ${ }^{1}$ Co Founder, Nanobi Data and Analytics Private Ltd., Bangalore, India \\ ${ }^{2}$ Director of MSc. Financial Mathematics Programme, Xi'an Jiaotong-Liverpool University, Suzhou, China \\ Email: jayaprakash@nanobianalytics.com, Michael.Ha@xjtlu.edu.cn
}

Received 8 July 2015; accepted 16 October 2015; published 23 October 2015

\section{Abstract}

Background: The 11 $1^{\text {th }}$ Annual Conference of Asia-Pacific Risk and Insurance Association was held on July 22-25, 2007 in Taipei, Taiwan. The first author participated in this annual conference where he met the second author who was invited to deliver two plenary speeches on Corporate Governance and Financial Institution Regulation [1] and Alternative Investments for Financial Institutions [2]. The first author was then working as consultant with i-flex solutions, a subsidiary of Oracle and the second author was Vice President of Strategic Business Initiatives Units at ING Life Insurance in its Taiwan operation. The two authors decided to start collaborating on a research paper titled "Modeling Policyholder Behavior through Insurance Resonant Marts for Pricing Options and Guarantees." The first version of the paper was submitted for research purposes to ING Insurance Risk Management Global Conference 2007 [3] which was held in Beijing, China. Although it was neither presented nor published, the working draft was constantly updated and revised. In 2015, after eight years of continuous research collaboration, the two authors decided to submit the final version of the paper to the $5^{\text {th }}$ World Congress on Engineering and Technology for scholarly presentation. Aim: The competition in the insurance industry is extremely fierce. Insurance companies are under tremendous pressure to retain and increase their customer base, to offer services at attractive rates and provide returns competitive with mutual funds, equities and banks, to achieve profitability across various lines of insurance, to comply with statutory norms etc. Despite having the best of breeds, such as accountants, actuaries [4], lawyers, underwriters, IT experts, consultants, etc., many insurance companies face severe problems to cope with and survive under such pressures. Insurance companies are now striving towards creating innovative products that can match the expectation of the customers with respect to investment returns and risk coverage at competitive rates, which is a very challenging task. Also it is very important to measure the expectations of the customers keeping in mind that those customers are already owners of other financial products. Pricing always follows the expectations and without proper data support, Model risk is imminent. Even if a product is correctly priced, without understanding the behavior of the policyholder towards various financial products will lead to heavy lapses [4]. The authors describe a new framework called UIRDM Approach (Unified Insurance Resonant Data Mart) for the insurance companies wherein this approach stresses the need to think beyond the insurance boundaries. 


\section{Keywords}

\section{Insurance, Investment, Policyholders, Options, Guarantees, Data, Resonant}

\section{Introduction}

The competition in the insurance industry is extremely fierce. Insurance companies are under tremendous pressure to retain and increase their customer base, to offer services at competitive rates and provide returns competitive with mutual funds, equities and banks, to achieve profitability across various lines of insurance, to comply with statutory norms etc. Despite having the best of breeds, such as accountants, actuaries, lawyers, underwriters, consultants, etc., many insurance companies face severe problems to cope with and survive under such pressures.

Although insurance companies have detailed customer information, the lack of proper analysis creates difficulties. Unlike other sectors, insurance companies' record information of clients that exhibit the aggregated customer profile attributes of various sectors [5] [6]. For example, it records information of a customer of a typical FMCG (Fast Moving Consumer Goods) or a Cellular company and on top of it, it also records information similar to the one recorded by hospitals, banks, investment companies etc. simply stating, it is a treasure of information to study the behavior of the people and understand their preferences.

It is also increasingly noticed that consolidation of financial services is happening around the globe wherein Asset Management subsidiary and Insurance arms are brought under the same umbrella of a holding company for better valuation of financial position. The difference between the banking and insurance are getting narrowed and mutual services have become the order of the day. Insurance companies are now striving towards creating innovative products that can match the expectation of the customers with respect to investment returns and risk coverage provided at competitive rates. This is a Herculean task as customers are more knowledgeable in investment and insurance products. This paper focuses on creating a framework for the insurance companies to model the pricing for options and guarantees [7].

\section{Insurance Environment}

\subsection{Pricing Options \& Guarantees}

As far as purchase of insurance is concerned, in more than $90 \%$ of the cases, the customers who purchase insurance policies for the first time in their life would have already experienced the product of any other financial services [8] [9]. For example, at least the customer would have experienced a banking product. So insurance will not be the first financial product of purchase. Hence it becomes detrimental to polarize the behavior of a policyholder cutting across financial products so as to model his behavior and design the products accordingly [10].

For example, the increased exposure of the customers to the stock markets is pushing insurance companies to go in for equity-linked insurance plans and guarantee features [7]. In order to offer competitive yet attractive and profitable guarantee plans, insurance company must perform a lot of analyses of the policyholders' behavior [6]. They may wish to follow a stochastic asset model to generate random scenarios of investment returns in future. Similarly, for meeting the expectations of the customers in stock market returns context, a lot of analyses are required in pricing financial options [11] [12].

In the above scenarios, the important question that needs to be answered is about the expectation of a customer from an insurance company that can match with his expectation from the similar environment. It is not a simple conclusion that we can derive. For example, if the mutual fund market provides an average investment return of $12 \%$ p.a., it does not mean that insurance company should provide a minimum annual return of $12 \%$. There are other factors that can be cross-subsidized to retain the customer or attract new customers. Identifying such factors is more important than making the customer a "GOOD BOY" among all financial conglomerates of the group. Else, a high-end loyal customer of a banking group or mutual fund, who is termed as a "GOOD BOY”, may behave differently with the insurance company and be termed as a "BAD BOY". A point to be noted here is that the customer is same, the group is same but his perception of the financial products offered by the same group is varying leading to his differential behavior. 
Insurance companies and/or their financial groups have enough data to identify the factors. However, due to the lack of technological implementation coupled with IT budget constraints, the majority of the insurers cannot get the required information residing in their in-house database systems, thereby falling under the category of "Data Rich but Information Poor". The authors try to identify some new approach called UIRDM Approach (Unified Insurance Resonant Data Mart) for insurance companies to solve the problems and end benefits of implementation, etc.

\subsection{The Expectation Disequilibrium}

The real mechanism of insurance should assure the safeguard of economy by making the people facing the risk come together and form a common platform wherein insurance companies should be a mean for it. At the same time, customers expect insurance companies to safeguard their risk and help them to plan for their risk exposures and provide risk diversification [11]. As long as there is equilibrium between these two parties, there should be no problem. But the above expectation is an ideal scenario and it is far away from the reality in the current world. As neither insurance company is equipped with enough safeguarding weapons due to lack of information (though it wishes to) nor the customers are equipped with the knowledge about their exact needs, there is equilibrium imbalance from both parties. The reasons for the same are many like

- Customers are busy with their daily activities and do not have enough time to think in the lines of Enterprise Risk Management [9] (at corporate level) and Personal Risk Management Plan [13] [14] (at individual level) except the ones stipulated under statutory norms, like motor insurance, machinery insurance, workers compensation insurance etc.

- Majority of the customers could not form an equation of Risk Exposed Vs Risk Covered, barring a few firms.

- In general, majority of the individuals and corporate struggle/not aware of formulating such equations for proper risk management. As a result, clustering the population on the basis of risk exposure basis becomes unrealistic.

- From the insurance company's point of view, the data gathered by them during risk coverage agreement represents only a small sample of the overall risk exposure which makes it difficult to generalize their models of pricing, reinsurance arrangement, marketing, competition etc.

- Even the data gathered by insurance companies are influenced by various moral hazard factors like Ex Ante Moral Hazards, Static Ex Post Moral Hazards, Dynamic Ex Post Moral Hazards etc. Due to lack of proper established mechanism, it becomes extremely difficult to quantify such risks and modeling it.

- Though there are many technological advancement to overcome hurdles, insurance companies face trouble in implementing the same due to various factors.

\section{Data Preparation}

\subsection{Grilled Data vs. Drilled Data}

Data, which remain as the life blood of any insurance company and which are very much required for pricing options and guarantees are typically, get stranded in different systems due to the following factors:

- Deployment of different application systems to meet the requirements of specific segment wherein the basis of the segments can be demography, product, pressure groups etc.

- Data in different formats that include even pictorial format.

- Product requirements of different nature from the users, customers, vendors, statutory at the time of launch and at different points of life cycle.

- Lack of system integration ability due to the factors like budget, infrastructure, vendor ability etc.

As a result, more detailed grilled data exists in different systems. But to think in the lines of Enterprise Risk Management (in both insurer \& customer perspective to have expectation equilibrium), the requirement of an insurance company will be drilled data on top of grilled data to analyze the performance of the company. Drilled data help to assess the expectations of the customers, to model various strategies etc. Grilled Data should ideally form basis for drilled data and the systems that are present should enable the same.

\subsection{Drilled Data from Data Warehouse}

The ideal scenario to get the drilled data will be from a data warehousing system wherein data from various sys- 
tems are pooled into an Enterprise Data Warehouse for analysis purposes. Sometime, depending upon the requirement Data Marts at smaller level can also be formed which will pool data not from all systems but from specific systems. This can be later extended to a level of Enterprise Data Warehouse. But much care has to be exercised in the formation of the required database that will be used for drilling purpose. Ideally such data should come from a Data warehouse system.

\section{Model}

\subsection{A New Concept of "Unified Insurance Resonant Data Mart" (UIRDM) for Modeling Customer Behavior}

We introduce a new concept of creating a data mart of Resonant Data that are available from various systems. In Physics, resonance is the tendency of a system to oscillate at maximum amplitude at a certain frequency, meaning the maximum level of energy is retained. This frequency is known as the system's resonance frequency.

The same can be extended to the insurance customers wherein customers who can match a particular product frequency can be identified through proper analysis. The set of customers can be identified through certain common parameters across various groups within the holding company viz. banks, insurance and Asset Management companies. In the system, the maximum level of customer information is retained and used.

This idea was sparked based on the research done by the first author in India on health insurance. During the research, it was found that majority of the people pay hefty premiums for life insurance but were not willing to pay any premium for health insurance as they do not get much tax saving benefits in it, even though the risk exposure for health is much higher than other forms of risks. In that sense, insurance companies fail to recognize the risk exposure of people i.e. overall view of an individual customer. It also infers that life insurance companies focus only on life insurance and general insurance companies focus only on non-life portfolios [15]. But none of the insurance companies try to create a scenario wherein their customers can view their risk exposure vis-à-vis their coverages. This should be done at least as an awareness initiative.

Similarly, it was found that many of the well-educated policyholders covered under health insurance as part of their corporate health insurance program are underinsured. During the research data collection, it was found that 48.9\% of the Group Health Insurance [16] policyholders were not interested in buying additional individual health insurance coverages with a view that their existing Group Health insurance coverages provided by their employers were sufficient. This infers the following:

- Failure in marketing mechanism to create awareness despite the receptive educated audience.

- Failure to create products that can match the needs of the remaining 51.1\% of the people.

- Unawareness about the unutilized market potential lying in non-conventional segments etc.

- Lack of analysis of data \& research to measure the expectations of customers.

This happens not only in developing countries like India, but also in developed countries like Australia wherein majority of the people are underinsured in the existing Medicare arrangement and spend out-of-pocket expenses during surgery/hospitalization etc. Insurance companies, with the help of technology, can identify the potential segments that are underinsured, can study the patterns of behavior to devise new marketing promotional programs for cross-sell, can design new products etc. to provide personalized insurance solution for its customers.

\subsection{Creating Unified Insurance Resonant Data Mart}

In the above example, it was found that there exists a large potential to sell individual health insurance policies among the corporate health insurance policyholder segment. But members of corporate health insurance program do not have awareness about their risk exposure vis-à-vis risk coverage. Insurance companies with the help of technology can help to create portfolio view for its customers to display the Risk Covered vs. Risk Exposed.

But for this, it has to merge the resonant data available from Group system \& Individual insurance system. The rules for pooling should be based on resonance factors that can help to cross-sell.

For example, by studying the behavior of the individual health insurance policyholders' behavior with respect to purchase ability, retention vis-à-vis their age, income level, demographic attributes geographical attributes etc. decisions can be arrived at. The same can be mapped with the behavior pattern of the Group health insurance policyholders. 
In Figure 1, data analysis can be performed at various levels based on the interest of the insurer. i.e. analysis can be made to equate the interests of Group A \& D or Group B \& C, or between individual policyholders and group policyholders as a whole etc. The scope of the Resonant Data mart can be decided based on the IT Budget allocations. Insurance can start with small Data mart that can be extended to the level of Enterprise Data Warehouse.

In a similar manner, customer data from Asset Management Companies \& Banks can be matched to find the pattern and design the product \& pricing accordingly. In this context, Group A can be either Group Insurance [16] or Asset Management companies or Bank. There may be a lot of practical problems in creating such resonate data mart. But it all depends on the factors listed for an ideal Data warehouse in the previous section.

\subsection{Need for Resonant Data Marts in Insurance}

Insurance industry has more merits compared to other sectors for achieving success in such an exercise because.

a. Like other financial services, insurance industry (barring commercial insurance) has only individuals as the base in both of its corporate \& retail insurance whereas in banking (the nature of corporate banking customer is different from retail banking customer).

b. These individuals do not have personalized view of their overall risk coverage across their individual and group insurance domains. They also have various perceptions towards investment returns from the financial products they purchase from insurance companies, mutual funds and banks.

c. The marts can also be expanded to include the specific data of the customers from the banking group and mutual fund group to which the insurance company belongs to. This should be done to study the pattern of behavior cutting across the various financial products of the group.

\section{An Example}

\subsection{Enabling Portfolio Views}

Assume an individual, Albert, took out a term insurance policy [6] [17] in 2000, a critical illness insurance policy [13] [14] in 2002 and a unit linked investment plan [13] [14] in 2003 from the same insurance company. In addition to the Group Life insurance plan [16] sponsored by his employer, he is also part of the group health insurance policy offered by his residential association. Let us assume that the insurance company maintains different system for group life insurance, group health insurance, investment plan and insurance product (4 different systems). Albert's insurance data, residing in 4 different systems, hinder the insurer from knowing hidden elements, such as:

- Intensity \& severity of the risk covered for Life [5] [6] [17];

- Potential opportunity for cross-selling and up-selling with respect to Albert and his family members. (For e.g. Albert's wife may be a professional but having no insurance coverage on her own.)

- Tracking Customer behavior across products and getting 360 degree view of the customer. Tracking in terms of his behavior towards investment patterns in their banking group, mutual fund group and insurance group (For e.g., Albert may be a good boy with respect to Investments product but may be a bad boy with respect to health insurance [6] [13] [14] due to claim frequency [17]). Also tracking can be made on various factors like Loyalty, Commitment and Trust, Privacy, Involvement in the marketing mix, Evaluation of recommended products and information, Development of preferences, Becoming aware of preferences, Evaluation of bundles etc.

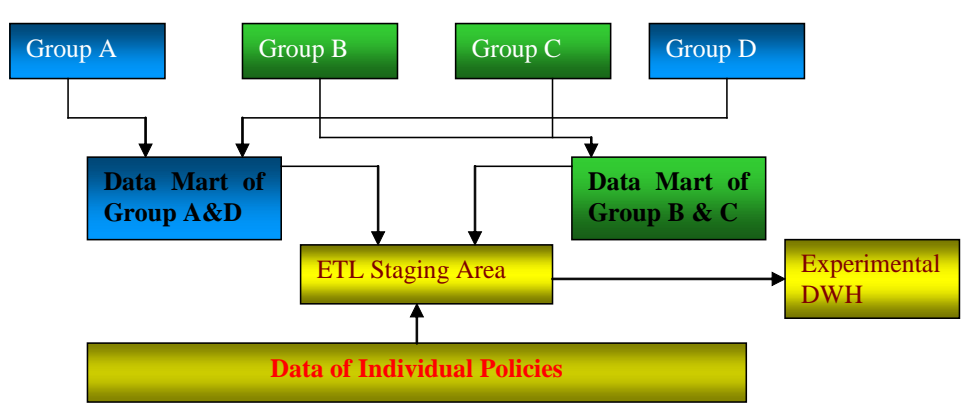

Figure 1. Enterprise data warehouse. 
- This paper does not suggest jumping into an enterprise data warehouse to analyze all customers but can create data marts extracting data from specific customers segments and expand it gradually to the level of enterprise data warehouse.

- Opportunity to enlighten customer about his total exposure in a single shot thereby enabling the customer to think in the lines of 'gaps in insurance coverage vis-à-vis risk exposure' and the expected investment behavior.

- Tracking of reinsurance requirements etc.

- Instantaneous update on product rules, underwriting rules and claim action rules based on the experience etc. Creating portfolio views goes one level higher than a mere customer id thereby creating a portfolio id for each customer and then pulling data pertaining to the customer residing in various systems (internally and externally) and storing in a data warehouse/data mart for analysis purposes. Multidimensional tools enable multi-dimensional analysis of the customer across various dimensions like age, gender, income level, number of dependents, latency, retention etc. to identify the patterns. This will help to model the pricing for options and guarantees [7].

\subsection{Analysis Classification}

Numerous Data mining techniques like Decision Tree, Cluster analysis, Discriminant analysis, context vector analysis, neural networks can be applied to the portfolio data that are integrated in the data warehouse.

\section{Conclusion}

With the growing threats to insurance industry in various forms which includes terrorism risks, catastrophic risks, pricing risks, customer attrition risks etc. it is very important for any insurance company to cement their base strongly to face the risks and price their product accordingly. Also it is very important to measure the expectations of the customers keeping in mind that those customers are already owners of other financial products. Pricing always follows the expectations and without proper data support, the risk of incorrect pricing is imminent. The UIRDM approach suggested in this paper is an attempt to define a framework wherein insurance analytics is taken beyond the logical campus of insurers to measure the behavior and fix price accordingly.

\section{Authors' Contributions}

The first author carried out the research and prepared the first draft and the second author verified the statistical results and edited the paper. Both authors have approved the final version of the manuscript.

\section{Acknowledgements}

The authors would like to thank Xian Jiaotong-Liverpool University and Nanobi Data and Analytics for supporting and sponsoring the presentation of this paper.

\section{References}

[1] Plenary Session 1, Corporate Governance and Financial Institution Regulation (2007) The $11^{\text {th }}$ Annual Conference of Asia-Pacific Risk and Insurance Association.

[2] Plenary Session 4, Alternative Investments for Financial Institutions (2007) The $11^{\text {th }}$ Annual Conference of AsiaPacific Risk and Insurance Association.

[3] (2007) ING Insurance Risk Management Global Conference.

[4] (1975) Relationship of the Actuary to the Policyholder. Record of Society of Actuaries, 1.

[5] Rejda, G.E. (1991) Social Insurance \& Economic Security. 4th Edition, Prentice-Hall.

[6] Black, K. and Skipper, H. (1987) Life Insurance. $11^{\text {th }}$ Edition, Prentice-Hall.

[7] Rufenacht, N. (2012) Implicit Embedded Options in Life Insurance Contracts. Physica-Verlag. http://dx.doi.org/10.1007/978-3-7908-2843-6

[8] Gerber, H.U. (1997) Life Insurance Mathematics. $3^{\text {rd }}$ Edition, Springer-Verlag. http://dx.doi.org/10.1007/978-3-662-03460-6

[9] Ha, M. (2007) Enterprise Risk Management and Strategic Asset Allocation in an Aging World. Ph.D. Thesis, Bulacan State University. 
[10] Trowbridge, C.L., FSA, MAAA, EA. (1989) Fundmental Concepts of Actuarial Science. Revised Edition, Actuarial Education and Research Fund.

[11] Panjer, H.H. (1998) Financial Economics with Applications to Investment, Insurance and Pensions. The Actuarial Foundation.

[12] McCutcheon, J.J. and Scott, W.F. (1994) An Introduction to the Mathematics of Finance. Butterworth Heinemann.

[13] Rejda, G.E. (2011) Principles of Risk Management and Insurance. $11^{\text {th }}$ Edition, Pearson.

[14] Vaughan, E.J. and Vaughan, T. (2008) Fundamentals of Risk and Insurance. $10^{\text {th }}$ Edition, John Wiley.

[15] Hart, D.G., Buchanan, R.A. and Howe, B.A. (1996) Actuarial Practice General Insurance. Institute of Actuaries of Australia, Sydney.

[16] Bluhm, W.F. (1992) Group Insurance. ACTEX Publications, Winsted, Connecticut.

[17] Ha, M. (2011) Lecture Notes for MTH305: Risk Management. Xian Jiaotong-Liverpool University. 